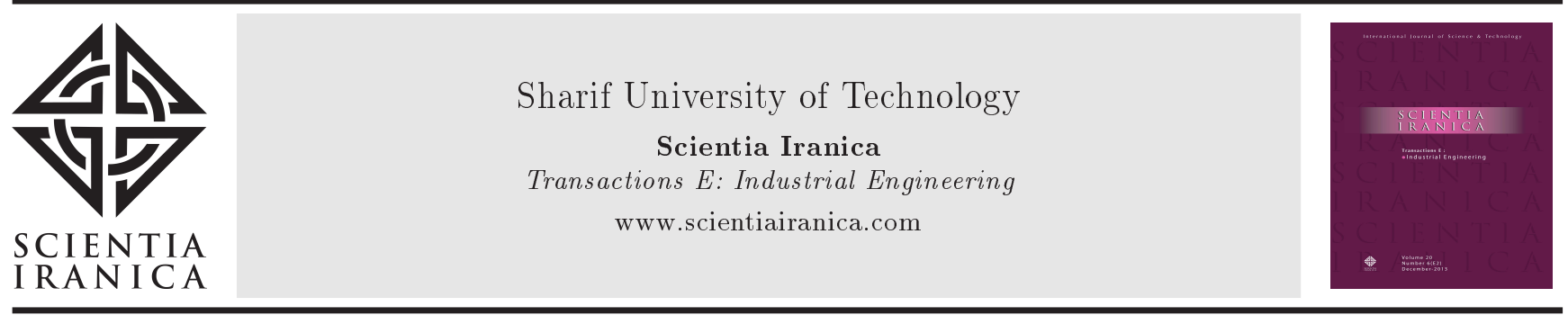

\title{
A computational approach to economic production quantity model for perishable products with backordering shortage and stock-dependent demand
}

\author{
H. Mokhtari ${ }^{a, *}$, A. Naimi-Sadigh ${ }^{\mathrm{b}}$ and A. Salmasnia ${ }^{\mathrm{c}}$ \\ a. Department of Industrial Engineering, Faculty of Engineering, University of Kashan, Kashan, Iran. \\ b. Iranian Research Institute for Information Science and Technology (IRANDOC), Tehran, Iran. \\ c. Department of Industrial Engineering, Faculty of Engineering and Technology, University of Qom, Qom, Iran.
}

Received 9 April 2016; received in revised form 26 June 2016; accepted 25 July 2016

KEYWORDS
Production-inventory;
EPQ;
Stock-dependent
demand;
Grid search;
Simulation-based
optimization.

\section{Introduction}

In today markets, the manufacturers are often encountered with high degrees of competition forcing them to improve their performance continuously. One of the main systems which greatly influences the performance of manufacturers is inventory system. Raw materials, sparse parts, work in processes, and finished goods are various types of inventory. The important decision in an inventory system is how many and when a company should order goods. If inventories are not controlled appropriately, they might become unreliable, inefficient, and costly. Since most companies in any

\footnotetext{
*. Corresponding author. Tel.: 03155912476

E-mail addresses: mokhtari_ie@kashanu.ac.ir (H.

Mokhtari);naimi@irandoc.ac.ir (A. Naimi-Sadigh);

a.salmasnia@qom.ac.ir (A.Salmasnia)
}

industrial sectors have some types of inventory, many studies have been conducted on different types of inventory systems so far. Although inventory problems are usually developed based on basic assumptions in earlier literature, they are still extensively employed by industries. The Economic Production Quantity (EPQ) model, also known as the Economic Manufacturing Quantity (EMQ), is one of the basic types of inventory model that determines the optimal production rate of an item for a facility. The aim of the EPQ model is often to optimize the total inventory and production cost, when items are processed internally instead of being provided from external sources. In some recent studies on the EPQ, Pan et al. [1] developed an integrated EPQ model with the statistical process control and maintenance issues. Additionally, Wee et al. [2] devised an economic production quantity model and a renewal reward theorem-based procedure for imperfect items 
with shortage and screening constraints. Dash et al. [3] proposed a deteriorating inventory model incorporating time-value of money with price-dependent demand and Discounted Cash Flows (DCF) approach. KarimiNasab and Sabri-Laghaie [4] designed an imperfect EPQ problem with random defectives, reworkable and non-reworkable items. Moreover, Nasr et al. [5] discussed an EPQ model with deteriorating raw material and analyzed the model via differential equations. Pacheco-Velazquez and Cardenas-Barron [6] analyzed an economic production quantity model by considering ordering and holding costs for both raw materials and finished products. Jawad et al. [7] developed an EPQ model based on the laws of thermodynamics focusing on the three pillars of sustainability and computed their costs. In addition, Sadeghi et al. [8] presented a multiitem economic production quantity model with fuzzy demand, backordering shortage, and limited space of warehouse. Al-Salamah [9] suggested an economic production quantity model for a case where the production process and inspection are both not perfect in order to find the optimal lot size for batch manufacturing while the batches are subjected to destructive or nondestructive acceptance quality control process.

Many researchers presented their work on the EPQ model by considering different parameters such as setup cost, rework process, scrap goods, inspection, deterioration, machine breakdown, backorder, shortage, etc. The majority of researchers on the EPQ models do not take into account the fact that customer behavior is not necessarily independent of system parameters. Traditional inventory models consider that the demand rate is constant [10], and some recent studies on the inventory models investigate the demand rate as a function of different variables such as price, advertisement, etc. [11-12]. However, all these models consider that the demand rate is independent of the inventory level. For certain types of products, the demand may be influenced by the inventory level. It has been observed that neglecting the effect of inventory systems on customer's behavior leads to poor performance of the inventory management system. Thus, the inventory systems with some dependence between the system parameters have received the researchers' attention in recent years. In such a situation, an increase in the product space usually has a positive impact on the sales of that product. It is usually observed by practitioners that a large amount of goods displayed in a supermarket attracts more customers, and conversely, low inventory of goods might make the perception that they are not fresh, and therefore decreases the demand. Consequently, building up the inventory often has a positive impact on the sales and profits. Therefore, in such a case, the demand has no longer a constant rate, but it depends on the inventory level. This case is known as stock-dependent demand or inventory-level- dependent demand in the inventory literature. As a result, many researchers have dedicated considerable attention to the inventory systems with a demand dependent on the stock level. Gupta and Vrat [13] were the first researchers that introduced inventory models with stock-dependent demand rate. Later, Recently, Chang et al. [14] have considered an EOQ model with stock-dependent demand and obtained the optimal replenishment policy while maximizing the total profit. In addition, Yang et al. [15] discussed an inventory model under inflation for stock-dependent consumption rate products with shortage. Shah et al. [16] derived optimal inventory policy for a price-sensitive and stock-dependent demand inventory system under a payment scheme. Sarkar and Sarkar [17] proposed an inventory model for deteriorating items with stockdependent demand, time-varying backordering, and time-varying deterioration rate to determine the optimal cycle length, such that the expected total cost is minimized. Soni [18] extended the previously proposed inventory model for deteriorating items under stockdependent demand and two-level trade credit. Singh and Sharma [19] presented a mathematical model for an inventory problem with stock-dependent demand and deterioration to analyze the retailer's optimal inventory policy under the permissible delay in payment. Krommyda et al. [20] studied a substitutable inventory management system where the demand for each product depends on the inventory levels. Wu and Zhao [21] suggested an economic order quantity model for deteriorating items with a current inventory-dependent and linearly increasing time-varying demand under trade credit. Tripathi and Singh [22] analyzed an inventory model with stock-dependent demand and different holding cost patterns. Tsoularis [23] considered the profit maximization inventory problem with the demand varied by price and stock availability. Chakraborty et al. [24] discussed multi-item integrated production-inventory models with stock-dependent demand and nonlinear cost functions. Recently, Palanivel and Uthayakumar [25] discussed an economic ordering quantity model with stock-dependent demand and imperfect products under the effect of inflation and time value of money.

Almost all physical items deteriorate over time, and the deterioration of physical goods cannot be disregarded. Consequently, a major issue of the inventory system in a business organization is the maintenance of perishable products inventories. Since deterioration often leads to decreasing the usefulness of the items over time, the deterioration is a major parameter in designing inventory systems. In such a case, deterioration is defined as decay, damage, spoilage, evaporation or loss of the marginal value of goods. The examples are drugs, volatile liquids, blood, vegetables, fruits, food products, photographic films, pharmaceuticals, chemi- 
cals, electronic goods, and radioactive substances. As a result, the inventory problem of perishable items has been studied by researchers. The work done by Ghare and Schrader [26] was the first attempt to design an optimal inventory system for perishable products where an inventory model with an exponentially deteriorating inventory was discussed. Afterwards, a comprehensive review of perishable literature till 2011 was provided by Goyal and Giri [27]. Later, Balkhi [28] discussed an inventory model for perishable products under supplier trade credits case considering time value of money. Bansal [29] developed the inventory model for deteriorating items under inflation. Vahdani et al. [30] discussed a single-item lot-sizing and scheduling problem with deteriorating inventory over time and multiple warehouses. Later, Bhaula and Kumar [31] provided an optimal inventory policy for two-parameter Weibull deterioration. Recently, Giri and Sharma [32] provided an integrated inventory model for a perishable item under allowable shortages and credit linked wholesale price assumptions. Li et al. [33] studied an EPQ model considering both product deterioration and deteriorating production system with rework. Jaggi, et al. [34] considered a two-warehouse manufacturing inventory model for deteriorating items with imperfect quality under permissible delay in payments to maximize the total profit per unit time. Moreover, Kouki et al. [35] modeled a coordinated inventory system for perishable items with random lifetime and positive lead time as a Markov process. Moreover, Teimoury and Kazemi [36] presented a two-stage supply chain, including a wholesaler and a retailer, which produces a single deteriorating product with a constant rate.

One of the factors that increases the complexity of the inventory systems is the uncertainty existing in the parameters and the input data. Numerous researchers have developed inventory models with stochastic demand functions. For example, Timmer et al. [37] analyzed the cooperation strategies for the continuous review inventory systems with Poisson demand. Juan et al. [38] designed a simheuristic algorithm by combining simulation and heuristics for solving a stochastic inventory problem considering distribution. Besides, Bieda [39] investigated an application of the stochastic approach to life cycle inventory data for a real case in Poland. Recently, Tamjidzad and Mirmohammadi [40] have discussed a single-item inventory system with resource constraint and quantity discount while considering stochastic demand. In addition, Wu et al. [41] proposed a supply chain problem of the coordination policy under vendor-managed consignment inventory subject to consumer return and stochastic demand. Purohit et al. [42] discussed an inventory lot-sizing and supplier selection problem considering time-varying stochastic demand. Chuang et al. [43] evaluated some models with stochastic ramp-type demand in the literature. In the current paper, in order to make the problem closer to real-world conditions, we assume a stochastic demand function.

In this paper, an appropriate productioninventory policy model based on a stochastic EPQ for a perishable product with tock-dependent demand is studied. It is assumed that shortages are allowed for the product and fully backordered. The main objective is to determine the optimal inventory cycle time and production quantity. The rest of this paper is organized as follows. Section 2 presents the notations and assumptions. The mathematical model is constructed in Section 3 while the solution algorithm is designed in Section 4. Section 5 discusses the experimental results. Finally, Section 6 concludes the paper.

\section{Model notations and assumptions}

The following notations are employed throughout the paper:

$P \quad$ Production rate per unit time

$\theta \quad$ Deterioration rate per unit time

$c \quad$ Production cost per unit

$h \quad$ Holding cost per unit per unit time

$b \quad$ Shortage cost per unit per unit time

$R \quad$ Setup cost per cycle

$k \quad$ Selling price per unit

$S \quad$ Shortage per cycle

$D(t) \quad$ Demand rate at time $t$

$\varepsilon \quad$ Stochastic term of the demand function

$I(t) \quad$ Inventory level at time $t$

A Constant term of the stock-dependent demand rate

$B \quad$ Coefficient of the inventory level in the stock-dependent demand function

$I_{\max } \quad$ Maximum inventory level

$t_{0} \quad$ Starting time of the planning horizon when the maximum shortage occurs

$t_{1} \quad$ The time when inventory becomes zero for the first time per cycle

$t_{2} \quad$ The time in which inventory reaches to its maximum level

$t_{3} \quad$ The time when inventory becomes zero for the second time per cycle

$T \quad$ Inventory cycle time

$I_{1}(t) \quad$ Inventory level at time interval $\left[t_{0}, t_{1}\right]$

$I_{2}(t) \quad$ Inventory level at time interval $\left[t_{1}, t_{2}\right]$

$I_{3}(t) \quad$ Inventory level at time interval $\left[t_{2}, t_{3}\right]$

$I_{4}(t) \quad$ Inventory level at time interval $\left[t_{3}, T+t_{0}\right]$

$T P\left(t_{1}, t_{3}\right) \quad$ Total profit per unit time 
The proposed model in this paper is developed based on the following assumptions:

1. The production-inventory system involves a single product;

2. The demand rate is sensitive to the stock level when $I(t) \geq 0$

3. The production rate is finite and constant;

4. The lead time is assumed to be zero;

5. Deterioration process occurs as soon as a product is produced;

6. Deterioration rate is constant over the time period;

7. There is no replacement or repair for deteriorating products over the time period and the deteriorated products are removed from the system immediately;

8. Shortages are allowed and fully backordered;

9. Setup cost is incurred per cycle;

10. Holding cost is only applied to the product units;

11. The demand function is stochastic.

\section{Model formulation}

The behavior of the production-inventory model is depicted by Figure 1. According to this model, the inventory system could be divided in four intervals. During time interval $\left[t_{0}, t_{1}\right]$, the inventory level increases due to the fact that the production rate is higher than the demand rate. At this interval, the demand rate is equal to constant A due to negative inventory level. Subsequently, on interval $\left[t_{1}, t_{2}\right]$, the inventory level continues to increase because the production rate is higher than the demand rate and the deterioration occurs until the inventory level reaches the maximum level $I_{\max }$. The demand rate is dependent on the stock $A+B I(t)$ at this interval. During the next time interval $\left[t_{2}, t_{3}\right]$, the inventory level decreases owing to the demand and deterioration rates till the inventory level becomes zero at time $t_{3}$. Finally, a shortage occurs as the demand grows only during time interval $\left[t_{3}, T+t_{0}\right]$. The shortage continues up to the end of the current inventory cycle.

The demand function is considered as follows:

$$
D(t)= \begin{cases}A+B I(t)+\varepsilon & I(t) \geq 0 \\ A+\varepsilon & I(t)<0\end{cases}
$$

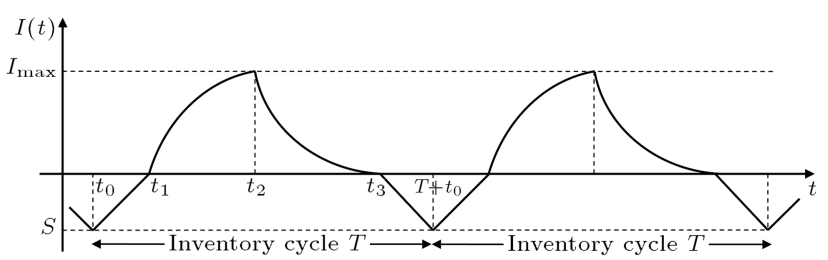

Figure 1. Inventory level illustration. where $\varepsilon$ represents the stochastic term of the demand function. It means that demand function, $D(t)$, is a stochastic variable with the expected value $E[D(t)]$ :

$$
E[D(t)]= \begin{cases}A+B I(t) & I(t) \geq 0 \\ A & I(t)<0\end{cases}
$$

and random term $\varepsilon$. Without loss of generality, let us assume that $t_{0}=0$ and $I_{1}(t)$ indicates the inventory level at time $t\left(0 \leq t \leq t_{1}\right)$, then we have:

$$
\frac{d I_{1}(t)}{d t}=P-D(t)=P-A \quad 0 \leq t \leq t_{1} .
$$

With boundary condition $I_{1}\left(t_{1}\right)=0$, it is concluded that:

$$
I_{1}(t)=(P-A)\left(t-t_{1}\right) \quad 0 \leq t \leq t_{1} .
$$

As it is obvious from Figure $1, I_{1}(0)=-S$; hence, it can be obtained that:

$$
S=(P-A) t_{1}
$$

Assume that $I_{2}(t)$ represents the inventory level at time $t\left(t_{1} \leq t \leq t_{2}\right)$, then we have:

$$
\frac{d I_{2}(t)}{d t}+\theta I_{2}(t)=P-D(t) \quad t_{1} \leq t \leq t_{2} .
$$

Considering $D(t)=A+B I(t)$ for $t_{1} \leq t \leq t_{2}$ and boundary condition $I_{2}\left(t_{1}\right)=0$, it is concluded that:

$$
I_{2}(t)=\left(\frac{P-A}{\theta+B}\right)\left[1-e^{(\theta+B)\left(t_{1}-t\right)}\right] \quad t_{1} \leq t \leq t_{2} .
$$

Let $I_{3}(t)$ represent the inventory level at time $t\left(t_{2} \leq\right.$ $\left.t \leq t_{3}\right)$, then it is concluded that:

$$
\frac{d I_{3}(t)}{d t}+\theta I_{2}(t)=-D(t) \quad t_{2} \leq t \leq t_{3} .
$$

Considering $D(t)=A+B I(t)$ for $t_{2} \leq t \leq t_{3}$ with the boundary condition $I_{3}\left(t_{3}\right)=0$ :

$$
I_{3}(t)=\frac{A}{(\theta+B)}\left[e^{(\theta+b)\left(t_{3}-t\right)}-1\right] \quad t_{2} \leq t \leq t_{3} .
$$

It is obvious from Figure 1 that $I_{2}\left(t_{2}\right)=I_{3}\left(t_{2}\right)=I_{\text {max }}$; therefore, we can obtain $t_{2}$ in terms of $t_{1}$ and $t_{3}$ as follows:

$$
t_{2}=\frac{-1}{(\theta+B)} \log \left[\frac{P}{A e^{(\theta+B) t_{3}}+(P-A) e^{(\theta+B) t_{1}}}\right] .
$$

By substituting $t_{2}$ into $I_{2}(t)$ or $I_{3}(t)$, maximum inventory level $I_{\max }$ can be calculated in terms of $t_{1}$ and $t_{3}$ as follows:

$$
I_{\max }=\frac{A(P-A)}{(\theta+B)}\left[\frac{e^{(\theta+B) t_{3}}-e^{(\theta+B) t_{1}}}{A e^{(\theta+B) t_{3}}+(P-A) e^{(\theta+B) t_{1}}}\right]
$$


Assume that $I_{4}(t)$ represents the inventory level at time $t\left(t_{3} \leq t \leq T\right)$, then we have:

$$
\frac{d I_{4}(t)}{d t}=-D(t)=-A \quad t_{3} \leq t \leq t_{4}
$$

With boundary condition $I_{4}\left(t_{3}\right)=0$, it is concluded that:

$$
I_{4}(t)=(-A)\left(t-t_{3}\right) \quad t_{3} \leq t \leq T .
$$

It is obvious from Figure 1 that $I_{1}(0)=I_{4}(T)=-S$; therefore, we can obtain $T$ in terms of $t_{1}$ and $t_{3}$ as follows:

$$
T=t_{3}+\left(\frac{P-A}{A}\right) t_{1}
$$

Since the production is carried out in interval $\left[0, t_{2}\right]$ with rate $P$, production quantity per cycle $Q$ is given by $P t_{2}$. Substituting $t_{2}$ into $Q$, it $\left(t_{2}\right)$ can be calculated in terms of $t_{1}$ and $t_{3}$. Therefore, all of the required information, including $I_{1}(t), I_{2}(t), I_{3}(t), I_{4}(t), I_{\max }$, $S$, and $Q$, are calculated in terms of $t_{1}$ and $t_{3}$. Hence, we can form the total profit in terms of $t_{1}$ and $t_{3}$ as follows:

(i) Setup cost per cycle $R$

(ii) Production Cost (PC):

$$
P C=c P t_{2} .
$$

Substituting $t_{2}$ into PC, it is concluded that:

$$
\begin{aligned}
\mathrm{PC}= & \frac{-c P}{(\theta+B)} \log \\
& {\left[\frac{P}{A e^{(\theta+B) t_{3}}+(P-A) e^{(\theta+B) t_{1}}}\right] . }
\end{aligned}
$$

(iii) Inventory Holding Cost $(\mathrm{HC})$ :

$$
\begin{aligned}
\mathrm{HC}= & h\left[\int_{t_{1}}^{t_{2}} I_{2}(t) d t+\int_{t_{2}}^{t_{3}} I_{3}(t) d t\right] \\
= & \frac{h}{(\theta+B)^{2}}\left[A\left(e^{(\theta+B)\left(t_{3}-t_{2}\right)}-1\right)\right. \\
& -A(\theta+B)\left(t_{3}-t_{2}\right) \\
& +(P-A)(\theta+B)\left(t_{2}-t_{1}\right) \\
& \left.+(P-A)\left(e^{-(\theta+B)\left(t_{2}-t_{1}\right)-1}\right)\right] .
\end{aligned}
$$

Substituting $t_{2}$ into $\mathrm{HC}$, the holding cost can be rewritten in terms of $t_{1}$ and $t_{3}$ as shown in Box I.

(iv) Shortage Cost (SC):

$$
\begin{aligned}
\mathrm{SC} & =b\left[\int_{0}^{t_{1}}\left[-I_{1}(t)\right] d t+\int_{t_{3}}^{T}\left[-I_{4}(t)\right] d t\right] \\
& =\frac{P b t_{1}^{2}(P-A)}{2 A} .
\end{aligned}
$$

(v) Sales Revenue (SR) is calculated based on the difference between the quantity of products produced per cycle and the quantity of products deteriorated per cycle:

$$
\begin{aligned}
\mathrm{SR}= & k\left[Q-\left(\int_{t_{1}}^{t_{2}} \theta I_{2}(t) d t+\int_{t_{2}}^{t_{3}} \theta I_{3}(t) d t\right)\right] \\
& -\frac{1}{(\theta+B)^{2}}\left[\theta ( A - P ) \left(e^{(\theta+B)\left(t_{1}-t_{2}\right)}\right.\right. \\
& \left.-\theta\left(t_{1}-t_{2}\right)-1\right) \\
& -\theta B(A-P)\left(t_{1}-t_{2}\right) \\
& -\theta A\left(e^{(\theta+B)\left(t_{3}-t_{2}\right)}+\theta t_{2}-\theta A t_{3}-1\right) \\
& \left.+\theta A B\left(t_{3}-t_{2}\right)\right]+P k t_{2} .
\end{aligned}
$$

Substituting $t_{2}$ into SR, it yields:

$$
\begin{aligned}
\mathrm{SR}= & \frac{k \theta}{(\theta+B)^{2}}\left(A \theta\left(t_{3}-t_{1}\right)+P \theta t_{1}\right. \\
& -\frac{P B}{\theta} \log \left(\frac{P}{A e^{(\theta+B) t_{3}}+(P-A) e^{(\theta+B) t_{1}}}\right) \\
& \left.-A B\left(t_{3}+(P-1) t_{1}\right)\right) .
\end{aligned}
$$

Hence, the total profit per time unit can be written as a function of $t_{1}$ and $t_{3}$ as follows:

$$
\mathrm{HC}=-\frac{P h \log \left[\frac{P}{A e^{(\theta+B) t} 3+(P-A) e^{(\theta+B) t_{1}}}\right]+A \theta\left(t_{3}-t_{1}\right)+A B h\left(t_{3}-t_{1}\right)+P h t_{1}(\theta+B)}{(\theta+B)^{2}} .
$$




$$
\begin{aligned}
& \mathrm{TP}\left(t_{1}, t_{3}\right)=\frac{\mathrm{SR}-D-\mathrm{PC}-\mathrm{HC}-\mathrm{SC}}{T} \\
& =\frac{1}{(\theta+B)^{2}\left(A\left(t_{3}-t_{1}\right)+P t_{1}\right)} \\
& \left(A P h-A D\left(\theta^{2}+B^{2}\right)-2 A \theta B D\right. \\
& +\left(A^{2} h(\theta+B)+(A \theta k)^{2}\right. \\
& \left.+A^{2} k^{2} \theta B\right)\left(t_{3}-t_{1}\right)+\left(-0.5 P^{2} b\left(\theta^{2}\right.\right. \\
& \left.+B^{2}\right)+0.5 A P b\left(\theta^{2}+B^{2}\right) \\
& +A \theta B P b(1-P)) t_{1}^{2}+A P(\theta+B) \\
& \left(h+\theta k^{2}\right) t_{1}+\frac{A P^{2} h e^{(\theta+B) t_{3}}}{A e^{(\theta+B) t_{3}+(P-A) e^{(\theta+B) t_{1}}}} \\
& -A P\left(B k^{2}-c(\theta+B)-h\right) \\
& \left.\log \left[\frac{P}{A e^{(\theta+B) t_{3}}+(P-A) e^{(\theta+B) t_{1}}}\right]\right) .
\end{aligned}
$$

This random demand function is utilized within all of the above equations. Hence, the total profit (Eq. (21)) has also a stochastic term because the demand function appears in its formulation. According to the above expressions, the problem can be formulated as a nonlinear optimization model with a stochastic demand function as follows:

Maximize $\operatorname{TP}\left(t_{1}, t_{3}\right)$

$$
\begin{aligned}
& \text { s.t. } \\
& t_{3} \geq t_{1} \quad t_{1}, t_{3} \geq 0
\end{aligned}
$$

\section{Solution algorithm}

A deep investigation into the problem formulated in the previous section reveals that it is rarely possible to obtain optimal production and inventory policies analytically. Additionally, the stochastic term of the demand function makes the problem more intractable. Therefore, we propose a computational approach as a simulation-based optimization algorithm to solve the problem. The simulation part is responsible for handling the uncertainty existing in the problem and evaluating the fitness function. In order to achieve the global optimal solution, a simulator is combined with an optimizer. The optimizer is utilized to find

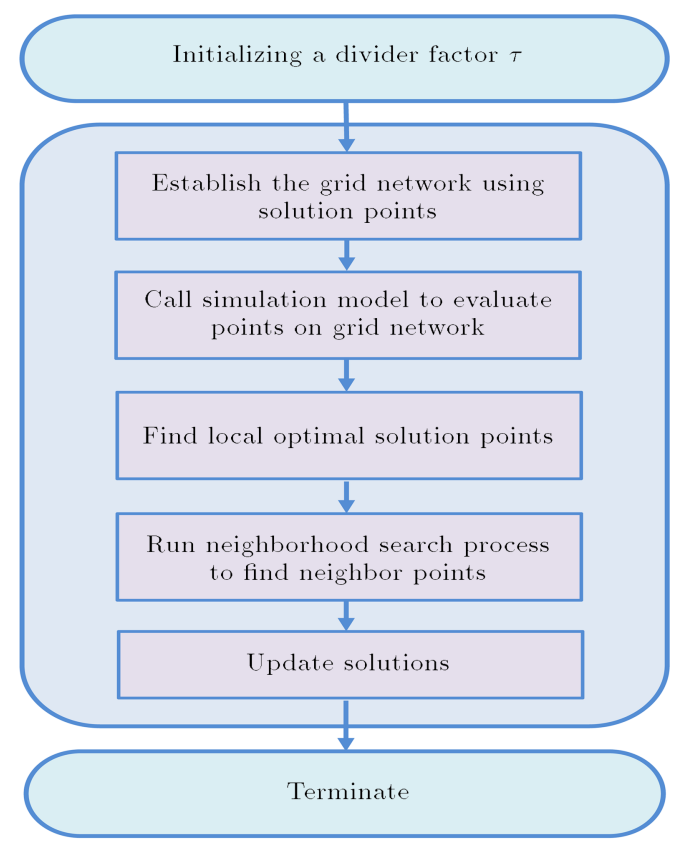

Figure 2. The solution algorithm flowchart.

the best set of the solutions, and then the simulation is used to evaluate the quality of the generated solutions and guide the search movements. The optimization part in the proposed simulation-based optimization approach aims to calculate the values of the decision variables. Our proposed approach considers a grid search as an optimizer. It first recognizes a feasible region with an equally divided grid, and then finds the best local solutions in that region. After that, it investigates the space around each local solution. During the search procedure, the algorithm may shift between spaces so as to find better solutions. Briefly, the algorithm consists of three main parts: (i) The initializing procedure; (ii) The neighborhood search process; and (iii) The simulation-based evaluation. Figure 2 presents a general procedure of the proposed approach.

\subsection{Initializing procedure}

The algorithm is initialized by selecting a divider factor, $\tau$, which is a real value. The grid network in our problem has two axes: $t_{1}$ and $t_{3}$. Figure 3 shows the structure of grid network in our problem.
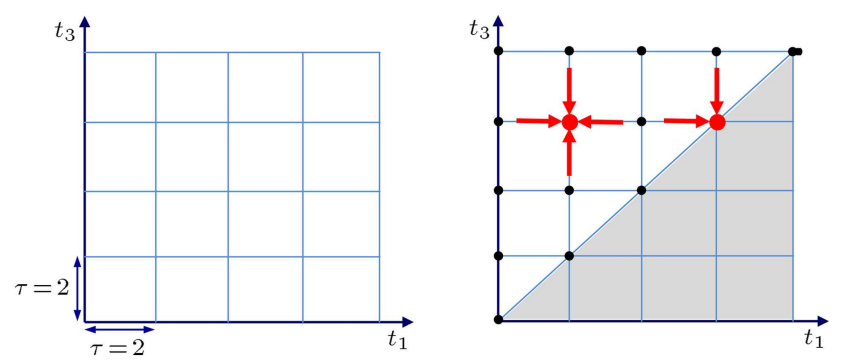

Figure 3. Grid network structure. 


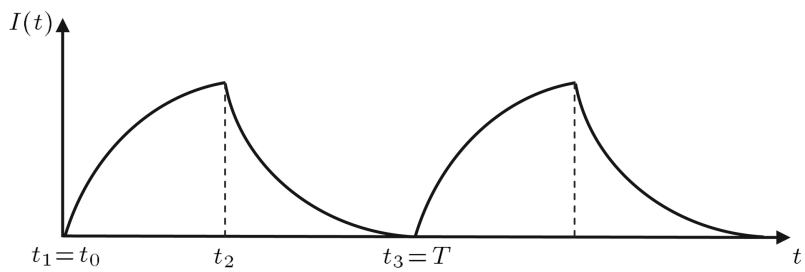

Figure 4. Inventory level for the case with $t_{1}=0$ and $t_{3}>0$.

The factor divides the axes of the grid network equally, and then creates the points by marking intersections of the horizontal and vertical grid lines. Figure 2 illustrates a grid network whose axes are divided by divider factor $\tau=2$. The algorithm recognizes the points that are feasible subject to constraint $t_{3} \geq t_{1}$. Figure 3 shows the feasible region of the grid network for the current problem. The set of feasible solutions is marked by the small dots in this figure. After that, all the feasible solutions in the grid network are evaluated by the simulator, and the fitness values are estimated. Here, we can identify the local optimal solutions by finding the points with greater fitness values among their neighbors. In Figure 3, the arrows show the directions where the fitness value of the feasible solutions increases. The local optimal solutions found so far are depicted by large dots in the grid network of Figure 3. These solutions are utilized as the initial solutions for the neighborhood search process. To this end, the smaller grid is formed around the local optimal solutions to further investigate the solution space.

For further analysis of the grid network, we consider two extreme cases in the solution space. Let us first consider a case in which $t_{1}=0$ and $t_{3}>0$. On the grid network, the corresponding point of this case lies on the vertical axes. In such a case, we have no shortage during the inventory cycle, and hence $t_{1}=t_{0}$ and $t_{3}=T$. This case occurs when the shortage cost is much greater than other cost parameters in the model. Figure 4 depicts the inventory curve for the first case.

As another extreme case, assume that $t_{1}=t_{3}$ with a value greater than zero. It means that we have no holding cost during the inventory cycle. On the grid network, the corresponding points of this case lie on 45-degree line. This case occurs when the holding cost is much greater than other cost parameters in the model. Figure 5 depicts the inventory curve for the second case.

\subsection{Neighborhood search process}

As described in the previous section, the simulationbased optimization initializes the local optimal solution and feeds it into the neighborhood search process as a starting point. Indeed, for each local solution, the algorithm utilizes the neighborhood search procedure and updates the best solution through an iterative

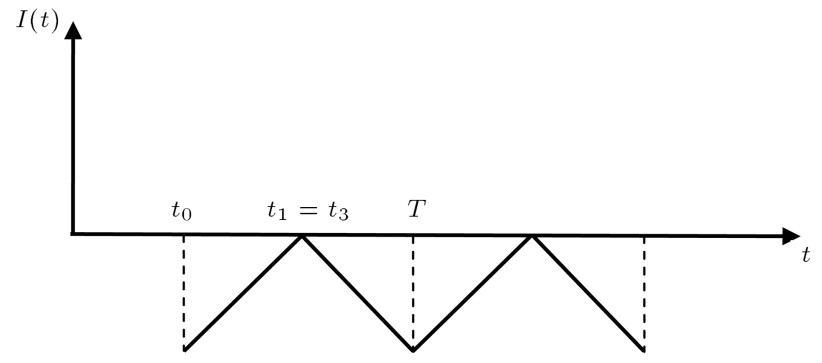

Figure 5. Inventory level for the case with $t_{1}=t_{3}$.

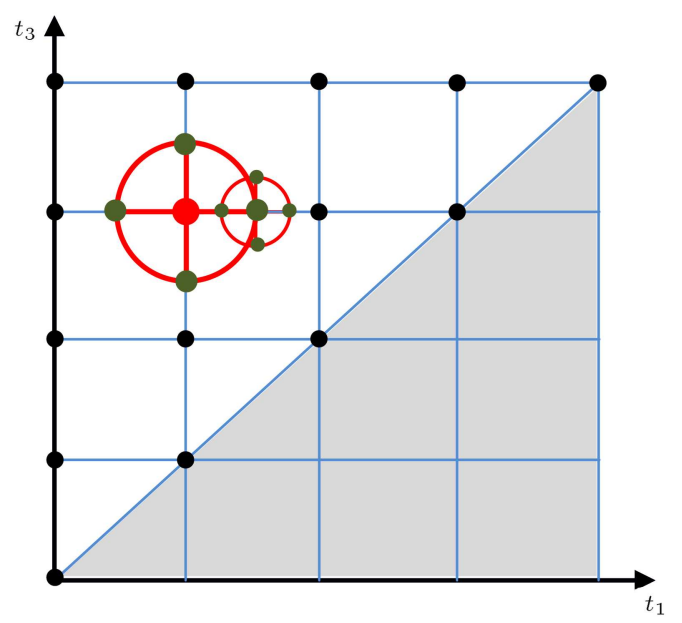

Figure 6. The neighborhood search process.

search procedure. For this purpose, neighborhood grids are established around each solution to search for better solutions. A neighborhood grid is a smaller grid network inside the master grid network whose center is placed on the current solution and includes new points on the interstitial points between the points around the current solution. As an example, Figure 6 shows a neighborhood grid. The green circles show new points found on the grid network to be further investigated. These interstitial green points are obtained by adding $\tau /(2$ Iter $)$ to the current solution where Iter represents the total number of iterations. Whenever the current solution is replaced by a new better solution, a neighborhood grid is established around the new solution. If there is no better solution than the current one on the neighborhood grid, a new narrower neighborhood grid is established around the current solution for further investigation.

\subsection{Evaluation by simulation}

This step uses simulation to estimate the total profit of a given set of solutions. As mentioned before, the complicated relationships and the uncertainty existing in the problem make it difficult to achieve the total profit via an analytical approach. In such a situation, simulation can reasonably estimate the objective function for each solution in the grid network and evaluate the quality of the solutions generated by the 


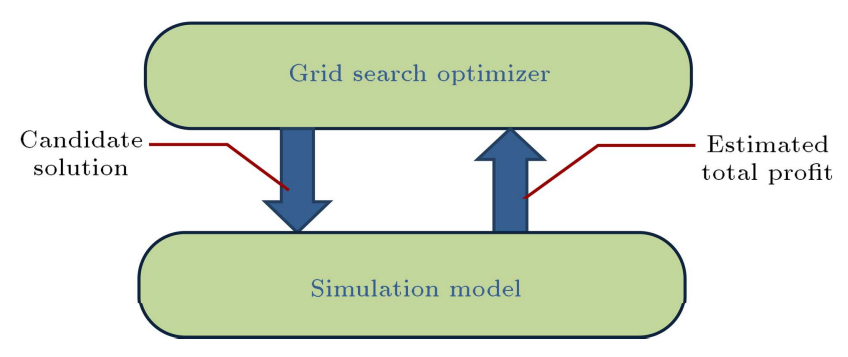

Figure 7. The simulation-based optimization procedure.

grid search. The simulation experiments are conducted several times. In each experiment, the demand function is randomly generated from the associated distribution and the total profit is estimated for the current solution. This brings about the conversion of the problem into a special deterministic one at each iteration. After all the experiments are implemented, the expected value of the total profit is calculated as the average amount of the special total profits estimated. Figure 7 depicts a general scheme of the simulationbased optimization procedure.

\section{Experimental results}

This section aims at discussing some experiments that have been carried out to investigate the performance of the proposed approach for the production-inventory problem. As mentioned earlier, it is rarely possible to analytically solve the current production-inventory problem for perishable products with shortage and stochastic stock-dependent demands. For further analysis, the shape of TP function is investigated for an instance problem. Figures 8 and 9 show the behavior of TP in terms of variables $t_{1}$ and $t_{3}$. These figures reveal that the Total Profit, TP, is neither concave nor convex globally. Moreover, as can be seen, it is not differentiable in some potentially optimal points, which makes the problem more intractable.

\subsection{A numerical example}

In this sub-section, we aim at presenting a numerical

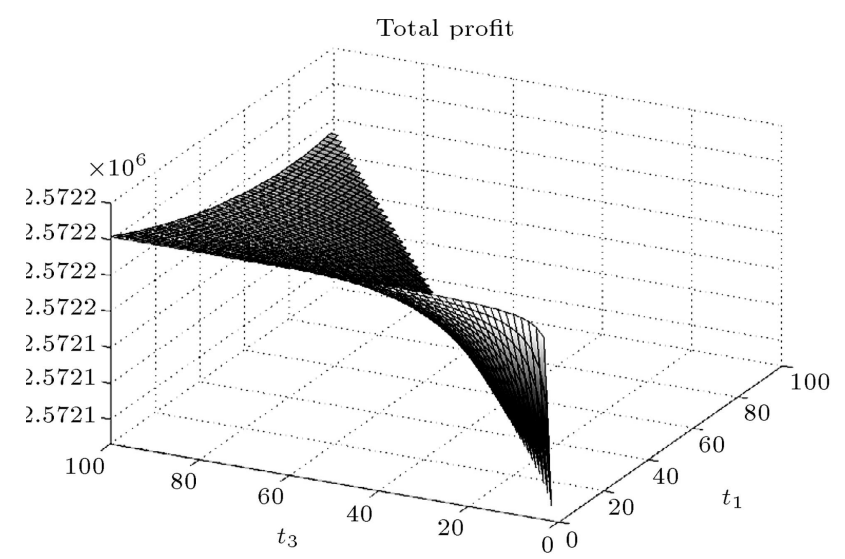

Figure 8. The total profit surface in terms of $t_{1}$ and $t_{3}$.

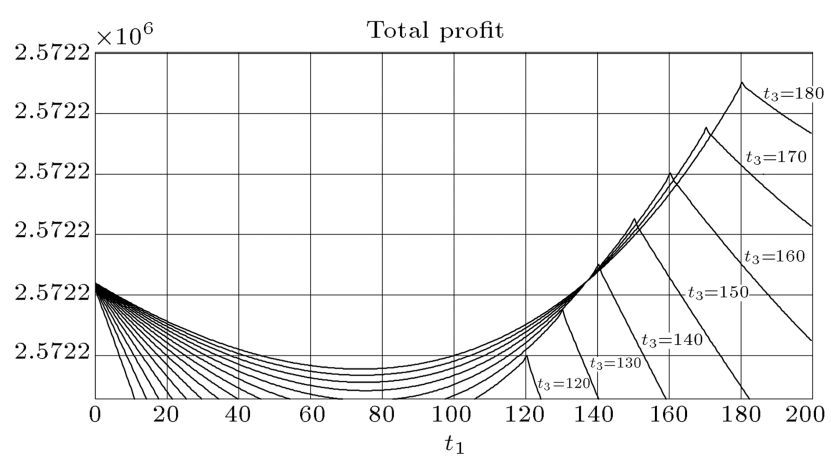

Figure 9. The total profit plot in terms of $t_{1}$ and $t_{3}$.

example in order to illustrate the procedure of the suggested approach step by step. The data considered in this example are as follows: production rate, $P=$ 300; constant term of the demand function, $A=50$; variable term of demand function, $B=8$; deterioration rate, $\theta=0.01$; selling price, $k=100$; holding cost, $h=2$; shortage cost, $b=20$; production cost, $c=50$; setup cost, $R=300$; and $\varepsilon$ follows the standard normal distribution, $N(0,1)$. To construct the mathematical model for this example, the inventory levels at cycle $T$ are obtained by substituting the above values. Then, to implement the simulation-based grid search, the inventory levels are used to compute the total profit function. The results of experiments for divider factor $\tau=10,25,40,60$ are shown by Tables 1-4. As can be seen, increasing divider factor leads to increasing the total profit for a fixed number of iterations (Iter $=$ $100)$ in this example. The best obtained solution is $t_{1}=0.0000, t_{3}=87.9802$ with $\mathrm{TP}=2974233.2264$ which is resulted from the algorithm with divider factor $\tau=60$. Moreover, Figures 10-13 show the convergence curves of the algorithm with different divider factors. As shown by these figures, the convergence behavior of the algorithm with the divider factor $\tau=60$ is outstandingly faster than other values.

\subsection{Sensitivity analysis}

This subsection aims at performing a sensitivity analysis on the various parameters using the numerical example discussed in the previous subsection. We set divider factor at $\tau=60$ in this subsection. The results of analysis are presented in Table 5 .

The output of the system considered here is the Total Profit, TP. The last column calculates the range of variations for the total profit by changing the parameters from $-20 \%$ to $+20 \%$. As the results show, the total profit is less sensitive to changes in $h, b$, and $D$. It is moderately sensitive to changes in $P, A, B, \theta$, and $c$, and highly sensitive to changes in $k$. Moreover, it reveals that there is an increase in the Total Profit, TP, value when $P, A, B, \theta$, and $k$ increase, and there is an increase in the Total Profit, TP, value when $h$, $c$, and $D$ decrease. 
Table 1. Results with divider factor, $\tau=10$.

\begin{tabular}{cccccc}
\hline \multirow{2}{*}{ Iteration } & \multirow{2}{*}{ Total profit } & \multicolumn{4}{c}{ Variables } \\
\cline { 3 - 6 } & & $\boldsymbol{t}_{\mathbf{1}}$ & $\boldsymbol{t}_{\boldsymbol{2}}$ & $\boldsymbol{t}_{\boldsymbol{3}}$ & $\boldsymbol{T}$ \\
\hline 1 & 1288565.709 & 20.0000 & 79.7763 & 80.0000 & 180.0000 \\
2 & 1393075.336 & 17.5000 & 79.7763 & 80.0000 & 167.5000 \\
3 & 1471213.485 & 15.8333 & 79.7763 & 80.0000 & 159.1667 \\
4 & 1535048.367 & 14.5833 & 79.7763 & 80.0000 & 152.9167 \\
5 & 1589772.141 & 13.5833 & 79.7763 & 80.0000 & 147.9167 \\
6 & 1638123.893 & 12.7500 & 79.7763 & 80.0000 & 143.7500 \\
7 & 1681737.761 & 12.0357 & 79.7763 & 80.0000 & 140.1786 \\
8 & 1721672.883 & 11.4107 & 79.7763 & 80.0000 & 137.0536 \\
9 & 1758657.993 & 10.8552 & 79.7763 & 80.0000 & 134.2758 \\
10 & 1793217.683 & 10.3552 & 79.7763 & 80.0000 & 131.7758 \\
$\vdots$ & $\vdots$ & $\vdots$ & $\vdots$ & $\vdots$ & $\vdots$ \\
99 & 2964436.736 & 0.0499 & 79.7763 & 80.9368 & 81.1863 \\
100 & 2964447.433 & 0.0499 & 79.7763 & 80.9868 & 81.2363 \\
\hline
\end{tabular}

Table 2. Results with divider factor $\tau=25$.

\begin{tabular}{cccccc}
\hline \multirow{2}{*}{ Iteration } & \multirow{2}{*}{ Total profit } & \multicolumn{4}{c}{ Variables } \\
\cline { 3 - 6 } & & $\boldsymbol{t}_{\mathbf{1}}$ & $\boldsymbol{t}_{\mathbf{2}}$ & $\boldsymbol{t}_{\boldsymbol{3}}$ & $\boldsymbol{T}$ \\
\hline 1 & 1604837.228 & 12.5000 & 74.7763 & 75.0000 & 137.5000 \\
2 & 2093205.03 & 6.2500 & 74.7763 & 75.0000 & 106.2500 \\
3 & 2609685.109 & 2.0833 & 74.7763 & 75.0000 & 85.4167 \\
4 & 2622819.157 & 2.0833 & 77.9013 & 78.1250 & 88.5417 \\
5 & 2632677.207 & 2.0833 & 80.4013 & 80.6250 & 91.0417 \\
6 & 2640487.929 & 2.0833 & 82.4846 & 82.7083 & 93.1250 \\
7 & 2921187.196 & 0.2976 & 82.4846 & 82.7083 & 84.1964 \\
8 & 2922291.842 & 0.2976 & 84.0471 & 84.2708 & 85.7589 \\
9 & 2923240.496 & 0.2976 & 85.4360 & 85.6597 & 87.1478 \\
10 & 2924068.796 & 0.2976 & 86.6860 & 86.9097 & 88.3978 \\
$\vdots$ & $\vdots$ & $\vdots$ & $\vdots$ & $\vdots$ & $\vdots$ \\
99 & 2973050.195 & 0.0069 & 87.5423 & 87.5697 & 87.8743 \\
100 & 2973062.647 & 0.0069 & 87.5660 & 87.5847 & 87.9993 \\
\hline
\end{tabular}

Table 3. Results with divider factor $\tau=40$.

\begin{tabular}{cccccc}
\hline \multirow{2}{*}{ Iteration } & \multirow{2}{*}{ Total profit } & \multicolumn{4}{c}{ Variables } \\
\cline { 3 - 6 } & & $\boldsymbol{t}_{\mathbf{1}}$ & $\boldsymbol{t}_{\mathbf{2}}$ & $\boldsymbol{t}_{\mathbf{3}}$ & $\boldsymbol{T}$ \\
\hline 1 & 2186325.369 & 5.0000 & 69.7763 & 70.0000 & 95.0000 \\
2 & 2238488.721 & 5.0000 & 76.4430 & 76.6667 & 101.6667 \\
3 & 2973114.378 & 0.0000 & 76.4430 & 76.6667 & 76.6667 \\
4 & 2973545.887 & 0.0000 & 80.4430 & 80.6667 & 80.6667 \\
5 & 2973874.085 & 0.0000 & 83.7763 & 84.0000 & 84.0000 \\
6 & 2974135.348 & 0.0000 & 86.6335 & 86.8571 & 86.8571 \\
7 & 2973907.711 & 0.0000 & 84.1335 & 84.3571 & 84.3571 \\
8 & 2974110.704 & 0.0000 & 86.3557 & 86.5794 & 86.5794 \\
9 & 2973928.490 & 0.0000 & 79.7763 & 84.5794 & 84.5794 \\
10 & 2973942.596 & 0.0000 & 86.1739 & 86.3975 & 86.3975 \\
$\vdots$ & $\vdots$ & $\vdots$ & $\vdots$ & $\vdots$ & $\vdots$ \\
99 & 2974215.932 & 0.0000 & 87.5664 & 87.5880 & 87.7780 \\
100 & 2974221.210 & 0.0000 & 87.6043 & 87.6080 & 87.9780 \\
\hline
\end{tabular}


Table 4. Results with divider factor $\tau=60$.

\begin{tabular}{cccccc}
\hline \multirow{2}{*}{ Iteration } & \multirow{2}{*}{ Total profit } & \multicolumn{4}{c}{ Variables } \\
\cline { 3 - 6 } & & $\boldsymbol{t}_{\mathbf{1}}$ & $\boldsymbol{t}_{\mathbf{2}}$ & $\boldsymbol{t}_{\mathbf{3}}$ & $\boldsymbol{T}$ \\
\hline 1 & 1091489.606 & 25.0000 & 29.7763 & 30.0000 & 155.0000 \\
2 & 2959577.777 & 10.0000 & 29.7763 & 30.0000 & 80.0000 \\
3 & 2964025.517 & 0.0000 & 29.7763 & 30.0000 & 30.0000 \\
4 & 2966479.443 & 0.0000 & 37.2763 & 37.5000 & 37.5000 \\
5 & 2968060.581 & 0.0000 & 43.2763 & 43.5000 & 43.5000 \\
6 & 2969177.433 & 0.0000 & 48.2763 & 48.5000 & 48.5000 \\
7 & 2970015.778 & 0.0000 & 52.5620 & 52.7857 & 52.7857 \\
8 & 2970672.806 & 0.0000 & 56.3120 & 56.5357 & 56.5357 \\
9 & 2971204.563 & 0.0000 & 59.6454 & 59.8690 & 59.8690 \\
10 & 2971645.770 & 0.0000 & 62.6454 & 62.8690 & 62.8690 \\
$\vdots$ & $\vdots$ & $\vdots$ & $\vdots$ & $\vdots$ & $\vdots$ \\
99 & 2974203.723 & 0.0000 & 86.6066 & 87.6272 & 87.8172 \\
100 & 2974233.226 & 0.0000 & 86.5896 & 87.6402 & 87.9802 \\
\hline
\end{tabular}

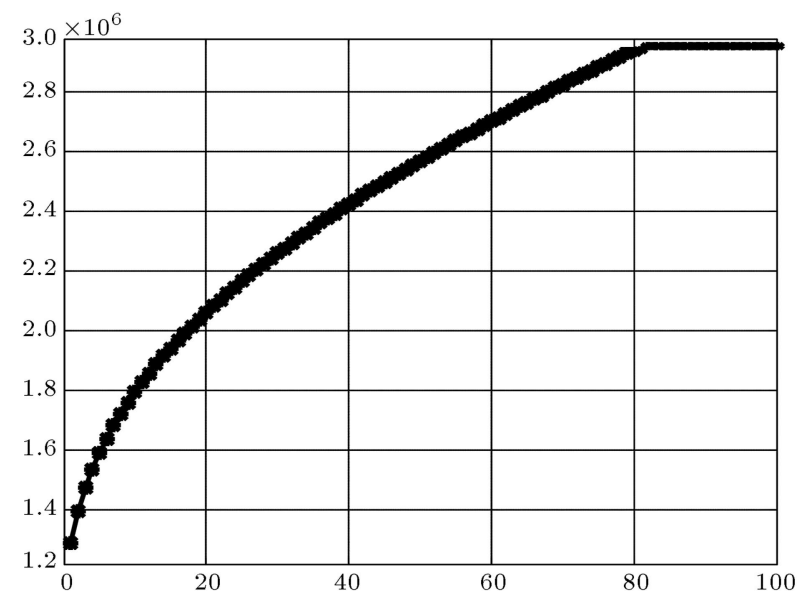

Figure 10. Convergence curve with divider factor $\tau=10$.

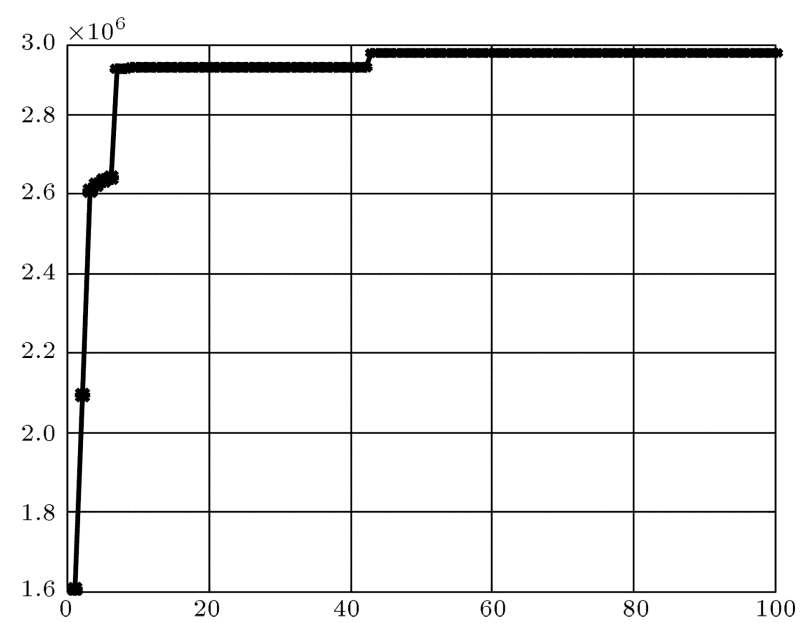

Figure 11. Convergence curve with divider factor $\tau=25$.

\subsection{Comparisons}

In order to investigate the quality of the solutions obtained by the suggested approach, the performances of a Genetic Algorithm (GA) and a full enumeration

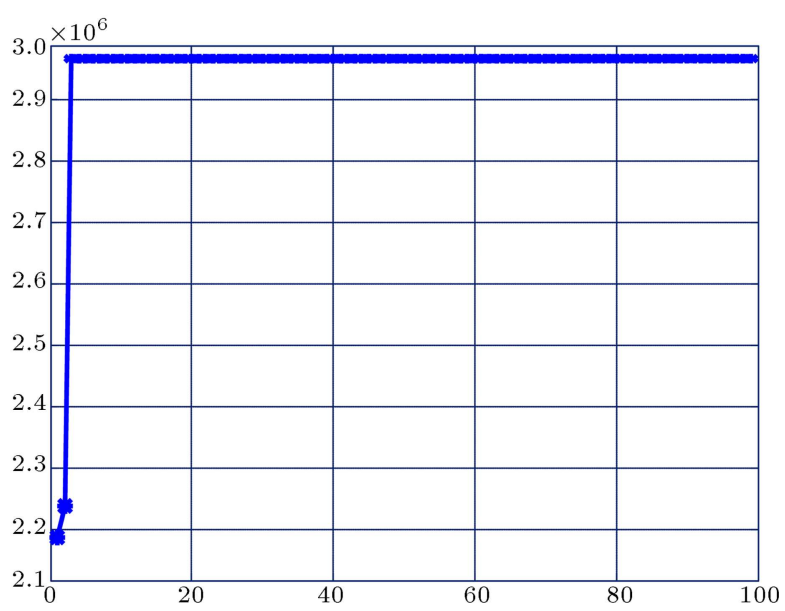

Figure 12. Convergence curve with divider factor $\tau=40$.

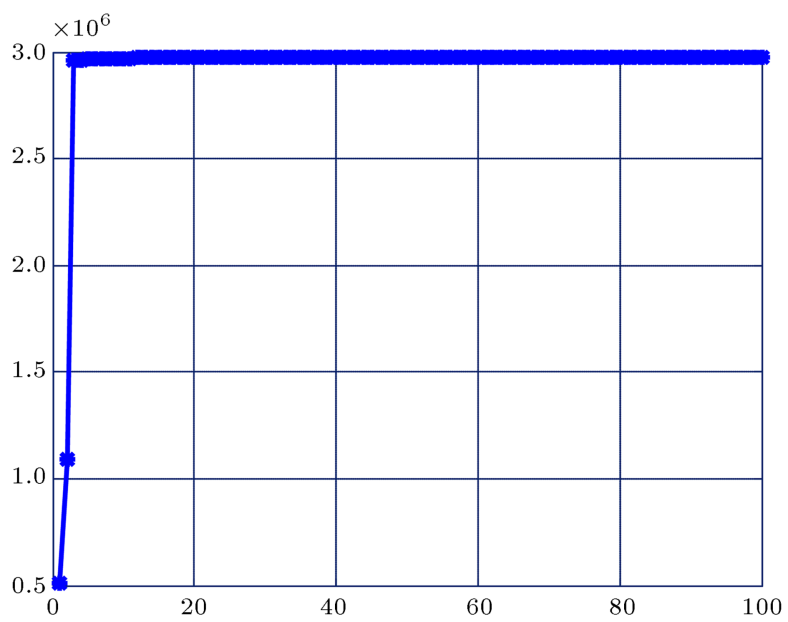

Figure 13. Convergence curve with divider factor $\tau=60$.

algorithm are compared with our approach in this subsection. To this end, the GA structure is devised as follows. The chromosome is designed by a string with 
Table 5. Sensitivity analysis results.

\begin{tabular}{ccccccc}
\hline $\begin{array}{c}\text { Parameter } \\
\text { change (\%) }\end{array}$ & $\mathbf{- 2 0 \%}$ & $\mathbf{- 1 0 \%}$ & $\mathbf{0}$ & $\mathbf{+ 1 0 \%}$ & $\mathbf{+ 2 0 \%}$ & $\begin{array}{c}\text { Percentage of } \\
\text { change in TP }\end{array}$ \\
\hline$P$ & 2973165.148 & 2973725.195 & 2974233.226 & 2974698.943 & 2975129.723 & $0.0661 \%$ \\
$A$ & 2973165.148 & 2973725.195 & 2974233.226 & 2974698.943 & 2975129.723 & $0.0661 \%$ \\
$B$ & 2973441.233 & 2973880.747 & 2974233.226 & 2974518.737 & 2974761.020 & $0.0444 \%$ \\
$\theta$ & 2973165.148 & 2973725.195 & 2974233.226 & 2974698.943 & 2975129.723 & $0.0661 \%$ \\
$k$ & 1898099.363 & 2406273.687 & 2974233.226 & 3601977.979 & 4289507.947 & $125.989 \%$ \\
$h$ & 2974245.672 & 2974239.449 & 2974233.226 & 2974227.003 & 2974220.780 & $-0.0008 \%$ \\
$b$ & 2974233.226 & 2974233.226 & 2974233.226 & 2974233.226 & 2974233.226 & $0.0000 \%$ \\
$c$ & 2975729.412 & 2975729.412 & 2974233.226 & 2972737.040 & 2971240.854 & $-0.1508 \%$ \\
$D$ & 2974233.908 & 2974233.567 & 2974233.226 & 2974232.885 & 2974232.544 & $-0.0000 \%$ \\
\hline
\end{tabular}

Table 6. The result of comparisons among full enumeration, genetic algorithm, and grid search.

\begin{tabular}{|c|c|c|c|c|c|c|c|c|c|c|c|c|}
\hline \multirow{3}{*}{$\begin{array}{c}\text { Problem } \\
\text { no. }\end{array}$} & \multirow{2}{*}{\multicolumn{2}{|c|}{ Selling Production }} & \multicolumn{6}{|c|}{ Full enumeration } & \multicolumn{2}{|c|}{ Genetic algorithm } & \multicolumn{2}{|c|}{ Grid search } \\
\hline & & & \multicolumn{2}{|c|}{ Grid size $=2$} & \multicolumn{2}{|c|}{ Grid size $=5$} & \multicolumn{2}{|c|}{ Grid size $=10$} & \multirow[b]{2}{*}{$\mathbf{T P}$} & \multirow[b]{2}{*}{$\begin{array}{c}\text { CPU } \\
(\mathrm{s})\end{array}$} & \multirow[b]{2}{*}{ TP } & \multirow[b]{2}{*}{$\begin{array}{c}\text { CPU } \\
(s)\end{array}$} \\
\hline & $\begin{array}{c}\text { price } \\
(k)\end{array}$ & $\begin{array}{l}\text { cost } \\
(c)\end{array}$ & TP & $\begin{array}{c}\text { CPU } \\
(\mathrm{s})\end{array}$ & $\mathbf{T P}$ & $\begin{array}{c}\text { CPU } \\
(\mathrm{s})\end{array}$ & TP & $\begin{array}{c}\text { CPU } \\
(\mathrm{s})\end{array}$ & & & & \\
\hline 1 & 50 & 15 & 99398 & 206.14 & 99398 & 49.67 & 99398 & 26.34 & 99398 & 113.14 & 99398 & 55.29 \\
\hline 2 & & 30 & 106234 & 218.87 & 106200 & 52.19 & 106254 & 25.75 & 106232 & 112.41 & 106234 & 53.65 \\
\hline 3 & & 45 & 68726 & 207.80 & 68719 & 48.92 & 68702 & 25.05 & 68678 & 112.36 & 68726 & 53.84 \\
\hline 4 & & 60 & 780597 & 208.57 & 780430 & 48.56 & 780115 & 25.64 & 780044 & 112.25 & 780597 & 53.54 \\
\hline 5 & 100 & 15 & 399398 & 205.12 & 399398 & 49.53 & 399398 & 25.24 & 399434 & 112.82 & 399408 & 52.79 \\
\hline 6 & & 30 & 598812 & 211.74 & 598823 & 49.87 & 598771 & 26.05 & 598652 & 112.63 & 598887 & 55.10 \\
\hline 7 & & 45 & 715025 & 231.49 & 714953 & 60.07 & 714834 & 27.57 & 714287 & 112.53 & 715034 & 54.07 \\
\hline 8 & & 60 & 1079243 & 216.11 & 1079100 & 49.10 & 1078935 & 25.67 & 1078965 & 113.08 & 1079251 & 55.41 \\
\hline 9 & 150 & 15 & 966655 & 207.03 & 966620 & 52.55 & 966570 & 27.60 & 966414 & 112.50 & 966664 & 52.74 \\
\hline 10 & & 30 & 1780862 & 209.45 & 1780600 & 52.06 & 1780400 & 25.33 & 1779383 & 113.13 & 1780875 & 56.18 \\
\hline 11 & & 45 & 2445542 & 209.27 & 2445200 & 59.48 & 2444700 & 25.69 & 2443134 & 112.60 & 2445582 & 56.21 \\
\hline 12 & & 60 & 3407145 & 215.63 & 3406800 & 50.23 & 3406262 & 26.16 & 3404735 & 112.71 & 3407182 & 55.63 \\
\hline 13 & 200 & 15 & 1823903 & 209.11 & 1823800 & 49.69 & 1823641 & 26.15 & 1823271 & 112.54 & 1823933 & 56.85 \\
\hline 14 & & 30 & 3435516 & 209.27 & 3435210 & 48.64 & 3434634 & 25.87 & 3432534 & 115.68 & 3436627 & 56.77 \\
\hline 15 & & 45 & 4868174 & 225.93 & 4867528 & 58.58 & 4866575 & 26.57 & 4864035 & 114.90 & 4868541 & 55.04 \\
\hline 16 & & 60 & 6666234 & 218.17 & 6665517 & 52.81 & 6664475 & 26.93 & 6659767 & 114.97 & 6666764 & 56.14 \\
\hline Average & & & 1827592 & 213.11 & 1827394 & 52.00 & 1827104 & 26.10 & 1826185 & 113.14 & 1827731 & 54.95 \\
\hline
\end{tabular}

two genes $\left\{t_{1}, t_{3}\right\}$. The initial population is produced by assigning a random real number to each gene. The crossover operates on two parent solutions, $P_{1}$ and $P_{2}$, in order to create new offspring solutions. For this purpose, a random number, $\lambda \in[0,1]$, is generated and the offsprings are obtained as $\lambda P_{1}+(1-\lambda) P_{2}$ and $\lambda P_{2}+(1-\lambda) P_{1}$. The mutation alters the value of the genes in order to make a random change to the solution. For this purpose, random binary number, $\gamma$, is generated and the mutation operator sets, $t_{1}=0$, if $\gamma=0$, and $t_{3}=t_{1}$; otherwise, the current solution $\left(t_{1}, t_{3}\right)$ is transmitted to the boundary of the feasible region $\left(t_{3} \geq t_{1}\right)$. For example, if we have $(2.5,4.0)$ as the current solution, mutation turns it to $(0.0,4.0)$ if $\gamma=0$, and to $(2.5,2.5)$ if $\gamma=1$. The standard features of the GA algorithm used in this subsection are as follows: crossover rate $=0.3$, mutation rate $=$ 0.1 , population size $=40$, generation number $=300$, and replication number $=5$. In order to implement the algorithms, we need a wide range of test problems. To this end, we generate the instances using the uniform distribution. We categorize the instances based on selling price, $k$, and production cost, $c$, as the most sensitive parameters.

Table 6 summarizes the results of the comparison for the suggested grid search with the genetic algorithm and the full enumeration algorithm in terms of the Total Profit (TP) and the CPU time. Since the performance of the full enumeration algorithm is greatly dependent on the grid size, we examine three values for 
the grid size $\{2,5,10\}$. As expected, among the three full enumeration algorithms, Grid size $=2$ obtained better solutions than the two others. As the results presented in this table reveal, the suggested grid search algorithm obtains better solutions compared to both the full enumeration and genetic algorithms with less computational time.

\section{Conclusions}

As marketing researchers have recognized, the demand for many products is directly proportional to the amount of stock displayed. It is usually observed by the practitioners that a large amount of goods displayed in a supermarket attracts more customers, and conversely, low inventory of goods might make the perception that they are not fresh, and therefore decrease the demand. Consequently, building up the inventory level often has a positive impact on sales and profits. Therefore, in such a case, the demand has no longer a constant rate, but it depends on the stock level. Hence, this paper dealt with a stockdependent demand for an EPQ model. The products are perishable and the shortage is permitted and fully backordered. In order to determine the appropriate production-inventory policies, the inventory level was formulated at different time horizons, and then the total profit function was derived. Since the problem is mathematically intractable, designing an analytical approach was a challenging task. Therefore, this paper developed a simulation-based optimization algorithm where a grid search was combined with a simulation model. The grid search plays the role of an optimizer to determine the values of the model variables, and the simulation model is utilized to evaluate the quality of the solutions obtained by the optimizer within an iterative procedure. A numerical example was discussed and a sensitivity analysis was carried out with respect to the parameters of the model. The results showed that the total profit is highly sensitive to changes in $k$ and moderately sensitive to changes in $P, A, B, \theta$, and $c$. Moreover, the results of a comparison study demonstrate that the suggested approach is superior to genetic algorithm and full enumeration algorithms in terms of both accuracy and efficiency features.

As for future study, it would be interesting to consider joint pricing and inventory policy. We also can extend the model by considering both stock- and price-dependent demand functions. As for another extension, the partial backordering can be investigated.

\section{References}

1. Pan, E., Jin, Y., Wang, S. and Cang, T. "An integrated EPQ model based on a control chart for an imperfect production process", International Journal of Production Research, 50(23), pp. 6999-7011 (2012).

2. Wee, H.M., Wang, W.T. and Yang, P.C. "A production quantity model for imperfect quality items with shortage and screening constraint", International Journal of Production Research, 51(6), pp. 1869-1884 (2013).

3. Dash, B., Pattnaik, M. and Pattnaik, H. "Deteriorated economic production quantity (EPQ) model for declined quadratic demand with time value of money and shortages", Applied Mathematical Sciences, 8(73), pp. 3607-3618 (2014).

4. Karimi-Nasab, M. and Sabri-Laghaie, K. "Developing approximate algorithms for EPQ problem with process compressibility and random error in production/inspection", International Journal of Production Research, 52(8), pp. 2388-2421 (2014).

5. Nasr, W.W., Salameh, M.K. and Moussawi-Haidar, L. "Integrating the economic production model with deteriorating raw material over multi-production cycles", International Journal of Production Research, 52(8), pp. 2477-2489 (2014).

6. Pacheco-Velazquez, E.A. and Cardenas-Barron, L.E. "An economic production quantity inventory model with backorders considering the raw material costs", Scientia Iranica, 23(2), pp. 736-746 (2016).

7. Jawad, H., Jaber, M.Y., Bonney, M. and Rosen, M.A. "Deriving an exergetic economic production quantity model for better sustainability", Applied Mathematical Modelling, 40(11-12), pp. 6026-6039 (2016).

8. Sadeghi, J., Akhavan Niaki, S.T., Malekian, M.R. and Sadeghi, S. "Optimising multi-item economic production quantity model with trapezoidal fuzzy demand and backordering: two tuned meta-heuristics", European J. of Industrial Engineering, 10(2), pp. 170-195 (2016).

9. Al-Salamah, M. "Economic production quantity in batch manufacturing with imperfect quality, imperfect inspection, and destructive and non-destructive acceptance sampling in a two-tier market", Computers \& Industrial Engineering, 93(1), pp. 275-285 (2016).

10. Wang, S.-P. and Lee, W. "A note on A two-level supply chain with consignment stock agreement and stock-dependent demand", International Journal of Production Research, 54(9), pp. 2750-2756 (2016).

11. Naimi Sadigh, A., Chaharsooghi, S.K. and Sheikhmohammady, M. "A game theoretic approach to coordination of pricing, advertising, and inventory decisions in a competitive supply chain", Journal of Industrial and Management Optimization, 12(1), pp. 337-355 (2016a). 
12. Naimi Sadigh, A., Chaharsooghi, S.K. and Sheikhmohammady, M. "Game-theoretic analysis of coordinating pricing and marketing decisions in a multi-product multi-echelon supply chain", Scientia Iranica E, 23, pp. 1459-1473 (2016).

13. Gupta, R. and Vrat, P. "Inventory model with multiitems under constraint systems for stock dependent consumption rate", Operations Research, 24(1), pp. 41-42 (1986).

14. Chang, C.T., Teng, J.T. and Goyal, S.K. "Optimal replenishment policies for non-instantaneous deteriorating items with stock-dependent demand", International Journal of Production Economics, 123(1), pp. 62-68 (2010).

15. Yang, H.L., Teng, J.T. and Chern, M.S. "An inventory model under inflation for deteriorating items with stock-dependent consumption rate and partial backlogging shortages", International Journal of Production Economics, 123(1), pp. 8-19 (2010).

16. Shah, N.H., Patel, A.R. and Lou, K.R. "Optimal ordering and pricing policy for price sensitive stock-dependent demand under progressive payment scheme", International Journal of Industrial Engineering Computations, 2(3), pp. 523-532 (2011).

17. Sarkar, B. and Sarkar, S. "An improved inventory model with partial backlogging, time varying deterioration and stock-dependent demand", Economic Modelling, 30(1), pp. 924-932 (2013).

18. Soni, N.H. "Optimal replenishment policies for deteriorating items with stock sensitive demand under two-level trade credit and limited capacity", Applied Mathematical Modelling, 37(8), pp. 5887-5895 (2013).

19. Singh, S.R. and Sharma, S. "Optimal trade-credit policy for perishable items deeming imperfect production and stock dependent demand", International Journal of Industrial Engineering Computations, 5(1), pp. 151168 (2014).

20. Krommyda, I.P., Skouri, K. and Konstantaras, I. "Optimal ordering quantities for substitutable products with stock-dependent demand", Applied Mathematical Modelling, 39(1), pp. 147-164 (2015).

21. Wu, C.F. and Zhao, Q.H. "An inventory model for deteriorating items with inventory-dependent and linear trend demand under trade credit", Scientia Iranica, 22(6), pp. 2558-2570 (2015).

22. Tripathi, R.P. and Singh, D. "Inventory model with stock dependent demand and different holding cost functions", International Journal of Industrial and Systems Engineering, 21(1), pp. 68-82 (2015).

23. Tsoularis, A. "An optimal inventory pricing and ordering strategy subject to demand dependent on stock level and price", International Journal of Mathematics in Operational Research, 7(5), pp. 595-608 (2015).
24. Chakraborty, D., Kumar Jana, D. and Kumar Roy, T. "Multi-item integrated supply chain model for deteriorating items with stock dependent demand under fuzzy random and bifuzzy environments", Computers \& Industrial Engineering, 88(1), pp. 166-180 (2015).

25. Palanivel, M. and Uthayakumar, R. "An inventory model with imperfect items, stock dependent demand and permissible delay in payments under inflation", RAIRO-Operations Research, 50(3), pp. 473-489 (2016).

26. Ghare, P.M. and Schrader, G.H. "A model for exponentially decaying inventory system", International Journal of Productions Research, 21(1), pp. 449-460 (1963).

27. Goyal, S.K. and Giri, B.C. "Recent trends in modeling of deteriorating inventory", European Journal of Operational Research, 134(1), pp. 1-16 (2001).

28. Balkhi, Z. "Optimal economic ordering policy with deteriorating items under different supplier trade credits for finite horizon case", International Journal of Production Economics, 133(1), pp. 216-223 (2011).

29. Bansal, K.K. "Inventory model for deteriorating items with the effect of inflation", International Journal of Application and Innovation in Engineering and Management, 2(5), pp. 143-150 (2013).

30. Vahdani, M., Dolati, A. and Bashiri, M. "Single-item lot-sizing and scheduling problem with deteriorating inventory and multiple warehouses", Scientia Iranica, 20(6), pp. 2177-2187 (2013).

31. Bhaula, B. and Kumar, M.R. "An economic order quantity model for weibull deteriorating items with stock dependent consumption rate and shortages under inflation", International Journal of Computing and Technology, 1(5), pp. 196-204 (2014).

32. Giri, B.C. and Sharma, S. "An integrated inventory model for a deteriorating item with allowable shortages and credit linked wholesale price", Optimization Letters, 9(6), pp. 1149-1175 (2015).

33. Li, N., Chan, F.T.S., Chung, S.H. and Tai, A.H. "An EPQ model for deteriorating production system and items with rework", Mathematical Problems in Engineering, 957970 (2015).

34. Jaggi, C.K., Eduardo Cárdenas-Barrón, L., Tiwari, S. and Shafi, A.A. "Two-warehouse inventory model for deteriorating items with imperfect quality under the conditions of permissible delay in payments", Scientia Iranica, 24, pp. 390-412 (2017).

35. Kouki, C., Zied Babai, M., Jemai, Z. and Minner, S. "A coordinated multi-item inventory system for perishables with random lifetime", International Journal of Production Economics, 181, pp. 226-237 (2016).

36. Teimoury, E. and Kazemi, S.M.M. "An integrated pricing and inventory model for deteriorating products in a two stage supply chain under replacement and shortage", Scientia Iranica, 24, pp. 342-354 (2017).

37. Timmer, J., Chess, M. and Boucherie, R.J. "Cooperation and game-theoretic cost allocation in stochastic 
inventory models with continuous review", European Journal of Operational Research, 231(3), pp. 567-576 (2013).

38. Juan, A.A., Grasman, S.E., Caceres-Cruz, J. and Bektas, T. "A simheuristic algorithm for the singleperiod stochastic inventory-routing problem with stock-outs", Simulation Modelling Practice and Theory, 46(1), pp. 40-52 (2014).

39. Bieda, B. "Application of stochastic approach based on Monte Carlo (MC) simulation for life cycle inventory (LCI) to the steel process chain: Case study", Science of the Total Environment, 481(1), pp. 649-655 (2014).

40. Tamjidzad, S. and Mirmohammadi, S.H. "An optimal ( $r, Q)$ policy in a stochastic inventory system with allunits quantity discount and limited sharable resource", European Journal of Operational Research, 247(1), pp. 93-100 (2015).

41. Wu, Z., Chen, D. and Yu, H. "Coordination of a supply chain with consumer return under vendor-managed consignment inventory and stochastic demand", International Journal of General Systems, 45(5), pp. 502516 (2016).

42. Purohit, A.K., Choudhary, D. and Shankar, R. "Inventory lot-sizing with supplier selection under nonstationary stochastic demand", International Journal of Production Research, 54(8), pp. 2459-2469 (2016).

43. Chuang, J.P.-C., Chou, W.-S. and Julianne, P. "Inventory models with stochastic ramp type demand", Journal of Interdisciplinary Mathematics, 19(1), pp. 55-64 (2016).

\section{Biographies}

Hadi Mokhtari is currently an Assistant Professor of Industrial Engineering in University of Kashan, Iran.
His current research interests include the applications of operations research and artificial intelligence techniques to the areas of project scheduling, production scheduling, and supply chain management. He also published several papers in international journals such as Computers and Operations Research, International Journal of Production Research, Applied Soft Computing, Neurocomputing, International Journal of Advanced Manufacturing Technology, IEEE Transactions on Engineering Management, Expert Systems with Applications and Scientia Iranica.

Ali Naimi-Sadigh is an Assistant Professor of Industrial Engineering in the Information Technology Management Faculty of the Iranian Research Institute for Information Science and Technology (IRANDOC). He received his $\mathrm{BS}, \mathrm{MS}$, and $\mathrm{PhD}$ degrees in Industrial Engineering from K.N. Toosi University of Technology, Amirkabir University of Technology, and Tarbiat Modares University, respectively. His research interests include pricing, supply chain, game theory, and optimization.

Ali Salmasnia is currently an Assistant Professor in University of Qom, Qom, Iran. His research interests include quality engineering, multi-response optimization, applied multivariate statistics, and multi-criterion decision making. $\mathrm{He}$ is the author or co-author of various papers published in Applied Soft Computing, Neurocomputing, IEEE Transactions on Engineering Management, International Journal of Advanced Manufacturing Technology, Applied Mathematical Modelling, Expert Systems with Applications, International Journal of Information Technology and Decision Making, and TOP. 